\title{
Health-Relevant Phenotypes in the Offspring of Mice Given CAR Activators Prior to Pregnancy ${ }^{\mathbb{S}}$
}

\author{
Karin Dietrich, Jan Baumgart, Leonid Eshkind, Lea Reuter, Ute Gödtel-Armbrust, Elke Butt, \\ Michael Musheev, Federico Marini, Piyush More, Tanja Grosser, Christof Niehrs, \\ Leszek Wojnowski, and Marianne Mathäs
}

\begin{abstract}
Department of Pharmacology (K.D., L.R., U.G.-A., P.M., T.G., L.W., M.Ma.) and Institute of Medical Biostatistics, Epidemiology and Informatics (F.M.), University Medical Center Mainz, Mainz, Germany; Translational Animal Research Center (J.B., L.E.), University

Medical Center, Johannes Gutenberg University Mainz, Mainz, Germany; Institute of Experimental Biomedicine II, University

Hospital Würzburg, Würzburg, Germany (E.B.); Institute of Molecular Biology, Mainz, Germany (M.Mu., C.N.); and Division of Molecular Embryology, German Cancer Research Center (DKFZ-ZMBH Alliance), Heidelberg, Germany (C.N.)
\end{abstract}

Received June 6, 2018; accepted August 22, 2018

\begin{abstract}
Hepatic induction in response to drugs and environmental chemicals affects drug therapies and energy metabolism. We investigated whether the induction is transmitted to the offspring. We injected 3-day- and 6-week-old F0 female mice with TCPOBOP, an activator of the nuclear receptor constitutive androstane receptor (CAR, NR113), and mated them 1-6 weeks afterward. We detected in the offspring long-lasting alterations of CAR-mediated drug disposition, energy metabolism, and lipid profile. The transmission to the first filial generation (F1) was mediated by TCPOBOP transfer from the FO adipose tissue via milk, as revealed by embryo transfer, crossfostering experiments, and liquid chromatography-mass spectrometry
\end{abstract}

\section{Introduction}

Activation of the nuclear receptors constitutive androstane receptor (CAR) and pregnane $\mathrm{X}$ receptor (PXR) by drugs and environmental pollutants induces the hepatic expression of genes involved in drug and energy metabolism (Prakash et al., 2015). This accelerates the disposition, and thereby reduces the efficacy, of numerous drugs, such as oral antiretrovirals, contraceptives, and immunosuppressants. Alterations in the metabolism of such endobiotics as steroids, bile acids, bilirubin, retinoids, carbohydrates, and lipids (Moreau et al., 2008) affect, among others, the risks of diabetes, obesity (Yang and Wang, 2014), and fatty liver disease (Yamazaki et al., 2007).

CAR target genes have been reported recently to undergo epigenetic imprinting following CAR activation (Chen et al., 2012; Tien et al., 2015; Li et al., 2016). This prompted us to assess the duration of

This work was supported by the German Research Foundation (DFG) grant MA6821/1-1 (to M. Mathäs), by internal funding of the Johannes GutenbergUniversity Mainz (to L. Wojnowski), by the Interdisciplinary Center for Clinical Research (IZKF Würzburg) funding Z-4/123 (to E. Butt) and by the International PhD Programme Mainz (to K. Dietrich and P. More). Data is in part included in the doctoral thesis of Karin Dietrich.

https://doi.org/10.1124/dmd.118.082925.

S This article has supplemental material available at dmd.aspetjournals.org. analyses. The important environmental pollutant PCB153 activated CAR in the $\mathbf{F 1}$ generation in a manner similar to TСРОВOP. Our findings indicate that chemicals accumulating and persisting in adipose tissue may exert liver-mediated, health-relevant effects on F1 offspring simply via physical transmission in milk. Such effects may occur even if treatment has been terminated far ahead of conception. This should be considered in assessing developmental toxicity and in the long-term follow-up of offspring of mothers exposed to both approved and investigational drugs, and to chemicals with known or suspected accumulation in adipose tissue.

ABBREVIATIONS: BPA, 4,4'-(Propane-2,2-diyl)diphenol; CAR, constitutive androstane receptor (NR1I3); DEHP, Bis(2-ethylhexyl) benzene-1,2dicarboxylate; F1, first filial generation; HDL, high-density lipoprotein; HFD, high-fat diet; HPLC-MS/MS, high-performance liquid chromatographytandem mass spectrometry; LDL, low-density lipoprotein; logP, logarithmic partition coefficient; PCB153, 2,2',4,4',5,5'-hexachlorobiphenyl; SD, standard diet; TCDD, 2,3,7,8-tetrachlorooxanthrene; TCPOBOP, 1,4-bis-[2-(3,5-dichloropyridyloxy)]benzene; VLDL, very low-density lipoprotein. 
(Hughes, 2014). The extent or even the mere existence of such transmission in mammals, including humans, is still contentious (Heard and Martienssen, 2014).

In the following, we report and describe the mechanism of healthrelevant phenotypes in the offspring of mice treated well ahead of pregnancy with CAR activators.

\section{Material and Methods}

\section{Animals}

All animal experiments have been carried out in accordance with the Guide for the Care and Use of Laboratory Animals as adopted and promulgated by the US National Institutes of Health, and were approved by the responsible local ethics committee (Landesuntersuchungsamt Rheinland-Pfalz, reference number 23 177-07/G 13-1-078). All animals were treated humanely with regard to the alleviation of suffering. C57BL/6J were obtained from Envigo (Venray, Netherlands) and CD1 from Janvier (Saint Berthevin, France). A maximum of five animals per cage were kept on a 12-hour light cycle at a temperature of $20-24^{\circ} \mathrm{C}$ and $45 \%-65 \%$ humidity. Females were housed individually beginning with the last 3 days before giving birth.

Induction of Mice. Newborn mice were injected with a volume of $10 \mu \mathrm{l} / \mathrm{g}$ using 30-guage needles, adult mice with 7 or $10 \mu \mathrm{l} / \mathrm{g}$ using 27 -guage needles. CAR inducers were injected as follows, except if stated otherwise: TCPOBOP $(1,4-B i s$ [2-(3,5-dichloropyridyloxy)]benzene; Sigma-Aldrich, Munich, Germany), $3 \mathrm{mg} / \mathrm{kg}$ in corn oil, single intraperitoneal injection to adult and newborn mice; PCB153 $\left(2,2^{\prime}, 4,4^{\prime}, 5,5^{\prime}\right.$-hexachlorobiphenyl), $100 \mathrm{mg} / \mathrm{kg}$ in corn oil, single intraperitoneal injection to adult mice; phenobarbital sodium salt (Sigma-Aldrich), $100 \mathrm{mg} / \mathrm{kg}$ in $0.9 \% \mathrm{NaCl}$, i.p. on three consecutive days. Phenobarbital injections to newborn mice were given subcutaneously and only once 5 days after birth.

Female mice used to obtain the first filial generation (F1) offspring were induced 1 week prior to mating with an uninduced male. Adult males were depleted of spermatozoa by housing with females for 1 day and injected the following day with ТСРОВOP or corn oil. Three, 19, and 31 days after TCPOBOP injection, each male was mated for 4 days with three age-matched, untreated, virgin females. The induction was confirmed in all experiments by measuring the expression of the CAR target Cyp2b10 using a TaqMan assay.

Diets. Animals were fed R/M-H Extrudat (cat. no. 1536; Ssniff, Soest, Germany). For experiments with mice on a high-fat diet [HFD; DIO-60 kJ\% fat (Lard), cat. no. E15742-34; Ssniff] the control group was fed an appropriate standard diet (SD; DIO LS-13 kJ\% fat, 11\% sucrose, cat. no. E15748-04; Ssniff). Food and water were provided ad libitum to all animals. In experiments with HFD, the diet was changed from the R/M-H Extrudat to HFD or SD simultaneously with the injection of the inducer in $\mathrm{F} 0$ animals.

Embryo Transfer. Seven-day-old female C57BL/6J mice were injected with TCPOBOP $(3 \mathrm{mg} / \mathrm{kg})$ in corn oil or with corn oil alone. Superovulation with pregnant mare serum gonadotropin (PMSG; $2.5-5$ IU; i.p.) and human chorionic gonadotropin (hCG; $2.5 \mathrm{IU}$; i.p.) was started 3 weeks later with subsequent mating with untreated males for 12 hours. Zygotes were removed 24 hours later, cultured to two-cell embryos, and transferred to the oviduct of pseudopregnant, narcotized [medetomidin $(0.5 \mu \mathrm{g} / \mathrm{g})$, midazolam $(5 \mu \mathrm{g} / \mathrm{g})$, and fentanyl $(0.05 \mu \mathrm{g} / \mathrm{g})$ ] 9-weekold CD1 mice pretreated with TCPOBOP or corn oil 1 week in advance. Postsurgery analgesia was conducted using metamizol (100 $\mu \mathrm{g} / \mathrm{g}$, by mouth $)$ and carprofen $(4.5 \mu \mathrm{g} / \mathrm{g}$, s.c.).

Crossfostering. Female C57BL/6J and CD1 mice were treated with TCPOBOP ( $3 \mathrm{mg} / \mathrm{kg}$ ) in corn oil or with corn oil alone 1 week prior to 12-hour mating with untreated males of the same strain. E19.5 C57BL/6J F1 mice were delivered by cesarian section and substituted for up to $50 \%$ of CD1 litters. All F1 animals were analyzed 6 days after birth.

Zoxazolamine Paralysis Assay. Paralysis was induced with a single dose of the skeletal muscle relaxant zoxazolamine (175 mg/kg, i.p.; Sigma-Aldrich) in $10 \%$ dimethyl sulfoxide in corn oil. Mice were then placed on their backs at a constant temperature of $24^{\circ} \mathrm{C}$. Paralysis time was defined and measured between the initiation of paralysis and the time point when the animal was able to right itself.

Glucose Tolerance Test. Mice were fasted for 16 hours prior to baseline glucose measurement with subsequent glucose injection (10\% glucose, i.p.). All mice of one sex received the same amount of glucose irrespective of body weight. The amount of glucose per mouse was calculated as a dose of $2 \mathrm{~g} / \mathrm{kg}$ of the mean body weight of the mice on standard diet of the respective sex (Ayala et al., 2010).
Glucose concentrations were measured using a CONTOUR XT glucometer (Bayer AG, Leverkusen, Germany) in blood samples collected from the tail 15, 30,60 , and 120 minutes following the injection.

\section{Serum Lipoprotein Profile}

Serum cholesterol lipoprotein profiles were determined by size-exclusion chromatography as described earlier (Parini et al., 2006; Gil-Pulido et al., 2017). In brief, $5 \mu \mathrm{l}$ of serum was fractionated using a Superose $63.2 / 300$ gel filtration column from GE Healthcare (Uppsala, Sweden) and phosphate-buffered saline, $\mathrm{pH} 7.4$, as elution buffer, delivered by a first pump (1525 binary pump; Waters, Eschborn, Germany) at a flow rate of $50 \mu \mathrm{l} / \mathrm{min}$. The separated lipoproteins were mixed in a T-tube with $50 \mu \mathrm{l} / \mathrm{min}$ of cholesterol reagent Chol (Roche, Mannheim, Germany) delivered by a second pump (1515 pump; Waters). Thereafter, the mixture went through a $500-\mu 1$ reaction coil peep tubing (internal diameter $0.75 \mathrm{~mm}$ ) at $37^{\circ} \mathrm{C}$ in a post-column reaction oven (Temperature Control Module II; Waters). Finally, absorption was measured with an UV-VIS detector at $500 \mathrm{~nm}$ (2489 UV/Visible Detector; Waters). Total run time for each sample was 60 minutes. Chromatograms were integrated by Waters Empower 3 software. Very lowdensity lipoprotein (VLDL), low-density lipoprotein (LDL), and high-density lipoprotein (HDL) concentrations were calculated by dividing the area under each pertinent peak through the area of all cholesterol peaks. Chromatograms for serum lipoprotein separation are shown in Supplemental Fig. 6.

\section{Western Blot}

Total protein $(20-50 \mu \mathrm{g})$ lysed in a sample buffer was loaded onto each lane, separated by SDS-PAGE, and transferred to polyvinylidene fluoride membrane by tank blotting. The antibodies used were as follows: anti-CYP2B10 (1:3000; cat. no. AB9916; Millipore, Darmstadt, Germany) and anti-GAPDH (1:20000; cat. no. sc-32233; Santa Cruz Biothechnology, Dallas, TX) with anti-rabbit (1:5000; cat. no. A0545; Sigma-Aldrich) and anti-mouse (1:10000; cat. no. A6782; Sigma-Aldrich), respectively. Bands were visualized by ECL+ detection method (FemtoMax, Rockland, Limerik, PA) using ChemiDoc XRS System with Quantity One (V 4.6.9; Bio-Rad, Munich, Germany) software. Densitometric analysis of the protein bands was done using Image Laboratory (V 4.1; Bio-Rad).

\section{RNA-Isolation and Real-Time Polymerase Chain Reaction}

Total hepatic RNA was isolated using TriFast (PeqLab, Erlangen, Germany) and $1 \mu \mathrm{g}$ was reverse-transcribed to cDNA using the High-Capacity cDNA Reverse Transcription Kit (Applied Biosystems/Thermo Fisher Scientific, Darmstadt, Germany). Cyp2b10 expression was quantified using TaqMan assays [primers (Chen et al., 2012), probe: 5' -[FAM]ACGTTCCTCTTCCAGTGCATCAC[BHQ1]-3'] on a StepOnePlus cycler (Applied Biosystems/Thermo Fisher Scientific). 18S rRNA (Mm03928990_g1; Applied Biosystems) was used as an internal control. The expression of Cyp $2 b 10$ was calculated using the $\Delta \Delta \mathrm{Ct}$ method (Livak and Schmittgen, 2001).

\section{RNA Seq Data Analysis}

Three- to four-day-old C57BL/6J mice were injected with TCPOBOP $(3 \mathrm{mg} / \mathrm{kg}$ in corn oil) or corn oil. The hepatic RNA from newborn F0 and F1 mice (5-6 days old) was isolated with RNeasyKit (Qiagen, Hilden, Germany) to meet higher quality needs, and the hepatic RNA from adult F0 and F1 mice ( 3 months old) was isolated as described in the preceding section. The RNA of two to six newborn or adult male mice was pooled for the F0 and F1 generations. Hepatic RNA samples were sequenced on Illumina HiSEq 2000 using paired-end library protocol (TruSeq RNA Library Prep Kit; Illumina, San Diego, CA), at the StarSEQ GmbH, Mainz, Germany. We aimed for a sequencing depth of 25-50 million reads. Quality of raw sequencing reads was assessed using FastQC (Babraham Bioinformatics, Cambridge, UK) and reads were mapped to the mouse reference genome (gencode release M12 GRCm38.p5) using STAR aligner [v2.5.3a; (Dobin et al., 2013)], with the option "-quantMode GeneCounts" to count the number of reads per gene. EdgeR [v3.20.1; (Robinson et al., 2010)] was used for differential gene expression analysis. Genes with fold changes higher than two adjusted by $P$ value below 0.05 were considered differentially expressed. Differentially expressed genes obtained from edgeR were uploaded to Ingenuity Pathway Analysis (https://www.qiagenbioinformatics.com/products/ingenuitypathway-analysis; Qiagen). The core analysis was performed using Ingenuity 
Knowledge Base as the reference set (accessible via the afore mentioned link). The analysis was restricted to human and mouse species and to the differentially expressed genes with fold change of at least two. Pathways and upstream regulators were compared among the experimental groups. The sequences and processed files containing the counts in TPM (Transcripts per Kilobase Million) have been deposited in NCBI's Gene Expression Omnibus (Edgar et al., 2002; Barrett et al., 2013) and are accessible through GEO Series accession number GSE109630 (https://www.ncbi.nlm.nih.gov/geo/query/acc.cgi?acc=GSE109630).

TCPOBOP Extraction from Adipose Tissue and High-Performance Liquid Chromatography-Tandem Mass Spectrometry Analysis

Epididymal fat pads were excised and melted at $60^{\circ} \mathrm{C}$. One hundred, twenty microliters of each sample were heated to $50^{\circ} \mathrm{C}$ in $5 \mathrm{ml}$ of $n$-Hexan and mixed. Samples were kept at $-20^{\circ} \mathrm{C}$ overnight and centrifuged at $2000 \mathrm{~g}$ for 5 minutes. Supernatant was kept at $-20^{\circ} \mathrm{C}$ overnight and centrifuged again. One milliliter of the supernatant was dried for 1.5 hours in a vacuum concentrator with vapor trap (SC 110 and RVT 100 Savant; Thermo Fisher Scientific, Waltham, MA), dissolved in $100 \mu \mathrm{l}$ acetonitrile/water $(1: 1)$ and centrifuged at $13,000 \mathrm{~g}$ for 2 minutes. Samples were kept at $-20^{\circ} \mathrm{C}$. Five microliters were taken from the liquid phase and analyzed by high-performance liquid chromatography-tandem mass spectrometry (HPLC-MS/MS) analysis. The separation was performed on an Agilent 1290 UHPLC system equipped with a ZORBAX RRHD SB-C18 column $(1.8-\mu \mathrm{m} 2.1 \times 50 \mathrm{~mm}$; Agilent Technologies, Santa Clara, CA) maintained at $30^{\circ} \mathrm{C}$. The running buffer and the solvent were (A) $5 \mathrm{mM}$ ammonium acetate at pH 6.9 and (B) acetonitrile. The separations were performed at a flow rate of $0.4 \mathrm{ml} / \mathrm{min}$ using the following gradients: $50 \%$ of solvent B from 0 to 2 minutes, linear increase to $95 \%$ of solvent B for next 3 minutes, and kept at $95 \%$ of solvent $\mathrm{B}$ for another 2 minutes. To recondition the column, the flow rate was then switched to $0.5 \mathrm{ml} / \mathrm{min}$ and washed with $50 \%$ of solvent B for 3 minutes. During the last minute, the flow rate was linearly decreased to the initial value of $0.4 \mathrm{ml} / \mathrm{min}$. The detection was performed on Agilent 6090 triple quadruple mass spectrometer operated in the positive ion mode, using the settings listed in Supplemental Table 4 and Supplemental Table 5.

\section{Statistics}

Data were analyzed with GraphPad Prism version 7.00 for Windows. Parametric or nonparametric tests were used according to the results of the Shapiro-Wilk test. Further statistical analysis and numbers of replicates are provided in the figure legends. Mixed models were fit to the mouse body-weight time-course data. In detail, the subsets split by diet (SD vs. HFD) were fit separately with modeling time and treatment as fixed-effects, and animal as random-effect. Data at time point 0 were excluded for this purpose, as the diet and treatment were applied after this initial measurement. For this purpose, the R statistical software (R Core Team, 2017) (https://www.R-project.org) and the lme4 package (Bates et al., 2015) were used. Throughout the analysis, a significance level $\alpha=0.05$ was chosen. Since no estimates of effect sizes were available from literature, the target group size was set to five animals. With this group size, the power to detect a standardized difference in means of 2 (Cohen's d) is $79 \%$ given an $\alpha$-level of $5 \%$, as computed with the function power.t.test in the statistics software R. We expected higher intragroup variance for bodyweight, glucose measurements, and serum lipids, and therefore strove to double the group size. The presented group sizes reflect the additional effect of variabilities in breeding success, survival rates, and sex distributions of litters.

\section{Results}

Transmission of Cyp2b10 Induction to F1 and Its Effects on Drug Metabolism. The transmission of drug effects to the next generation was first assessed for the prototypical murine CAR-ligand 1,4-bis-[2-(3,5-dichloropyridyloxy)]benzene (TCPOBOP) and the CAR target gene Cyp2b10. Six-day-old F1 offspring of F0 females injected once with $3 \mathrm{mg} / \mathrm{kg}$ TCPOBOP 1 week prior to mating at the age of 8 weeks exhibited 747-fold (females) and 517-fold (males) increased Cyp 2 b10 mRNA expression compared with the female or male offspring of corn oil (vehicle)-injected females (Fig. 1A, left panel), respectively. The induction of the CYP2B10 protein was confirmed by Western blot
(Fig. 1A, right panel). In 8-week-old F1 offspring, the Cyp2b10 mRNA expression was still increased 3.8 -fold in females and 37 -fold in males (Fig. 1B). To extend further the interval between the TCPOBOP treatment and the time point of the F1 induction measurement, we injected 3-day-old female F0 mice with the same TCPOBOP dose as above and mated them 6 weeks later with untreated males. The Cyp $2 b 10$ mRNA expression was induced 2.3-fold in the female F1 offspring and 3.7-fold in the male F1 offspring 12 weeks after birth (Fig. 1C). In agreement with previous studies (Chen et al., 2012; Li et al., 2016), we found a robust and longlasting Cyp $2 b 10$ induction also in F0 females injected with TCPOBOP either as newborns or as adults (Supplemental Fig. 1). Among other Cyp genes, we found a 30-fold induction of Cyp2c55 in newborn but not in adult $\mathrm{F} 1$ offspring of TCPOBOP-treated females.

To determine the induction transmission through the paternal line, males were treated 3, 19, and 31 days prior to mating, to expose to TCPOBOP spermatozoa/spermatids, spermatocytes, and spermatogonia, respectively. There was a statistically significant induction in offspring generated with TCPOBOP-treated spermatocytes, but its 2-fold magnitude was negligible (Supplemental Fig. 2).

The impact of the transmitted CYP2B10 induction on F1 drug metabolism was assessed as the duration of paralysis upon injection of the muscle relaxant and CYP2B10 substrate zoxazolamine. The paralysis time was defined as the time required by the F1 mice to consciously right themselves. The paralysis time was $55 \%$ shorter in the female F1 offspring of F0 females treated with TCPOBOP 1 week prior to mating compared with the female $\mathrm{F} 1$ offspring of control $\mathrm{F} 0$ females. An effect of similar magnitude (40\%) in the male F1 offspring failed to reach the preset significance level (Fig. 2).

TCPOBOP Effects on Energy Metabolism in the F1 Offspring. The 12-week-old F1 offspring of TCPOBOP-treated F0 females gained less weight when set on a standard diet at the age of 6 weeks, but there was no difference between offspring of treated and untreated females when set on a high-fat diet (males Fig. 3A, females Supplemental Fig. 3A). The food intake was similar in the F1 offspring of TCPOBOP- and corn oil-treated females (Supplemental Fig. 4). Glucose tolerance was improved only in the male F1 offspring of TCPOBOP-treated F0 females, when the offspring were kept on HFD diet and only at one time point (males Fig. 3B, females Supplemental Fig. 3B). The F1 offspring of TCPOBOP-treated F0 females also displayed decreased total cholesterol and HDL levels, whereas LDL and VLDL levels were unchanged (Fig. 3C). These phenotypes mostly resembled the TCPOBOP effects in male F0 mice 3 days after the injection (Supplemental Fig. 5). (F0 females did not tolerate diet change following TCPOBOP injection.) The only exception was that TCPOBOP reduced weight gain irrespective of the diet and that it additionally reduced LDL (Supplemental Fig. 5).

We compared these phenotypes with gene expression changes in livers of male mice induced with TCPOBOP as newborns and analyzed 8 weeks later, as well as in 6-day- and 8-week-old male F1 offspring of TCPOBOP-treated females. Ingenuity Pathway Analysis revealed changes in pathways related to energy metabolism in all TCPOBOP groups, including CAR itself and known CAR signaling partners peroxisome proliferator-activated receptor $\alpha(\operatorname{PPAR} \alpha)$, liver X receptor (LXR), nuclear factor (erythroid-derived 2)-like 2 (NRF2), farnesoid X receptor (FXR), interleukin 6 (IL6), hepatocyte nuclear factor $4 \alpha$ (HNF4A) (Supplemental Tables 1 and 2). Among the five categories of functions and diseases affected by TCPOBOP were lipid and drug metabolism (Supplemental Table 3).

Long-Term CAR Activation in F1 by Transmission of the Lipophilic CAR Ligand via Milk. The transmission of TCPOBOPdriven induction to $\mathrm{F} 1$ could result from epigenetic modifications in maturating oocytes that happen as early as the injection of newborn 


\section{A 6-day-old F1 (F0 adults injected)}
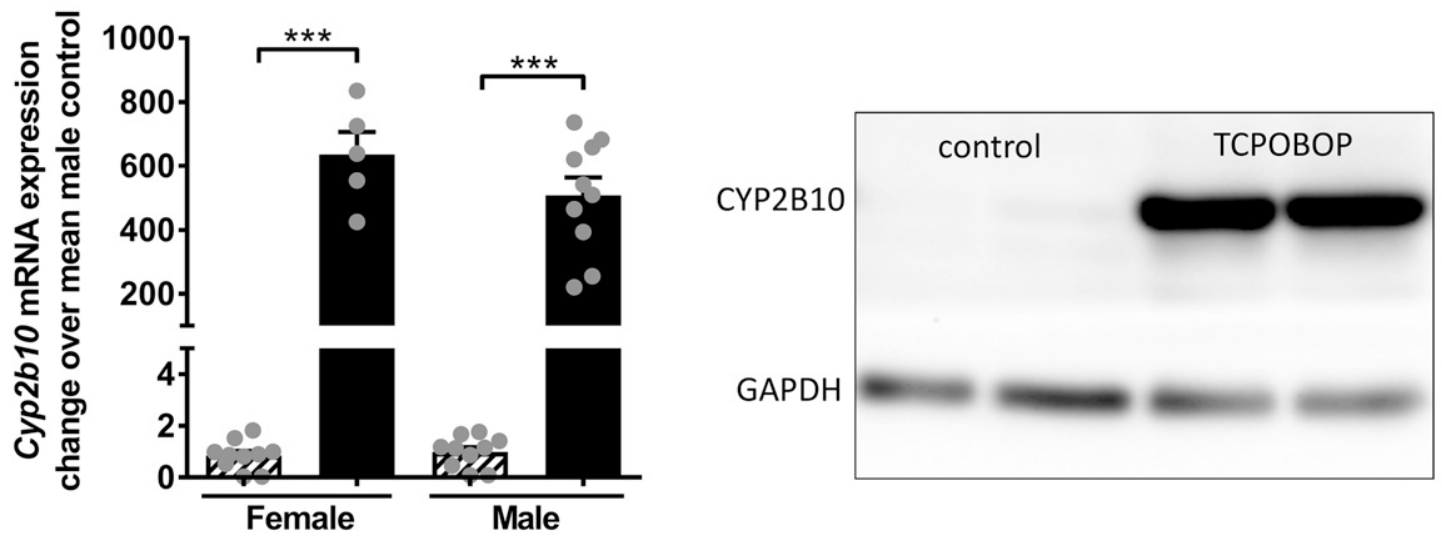

\section{B 8-week-old F1 (F0 adults injected)}

\section{12-week-old F1 (F0 newborns injected)}
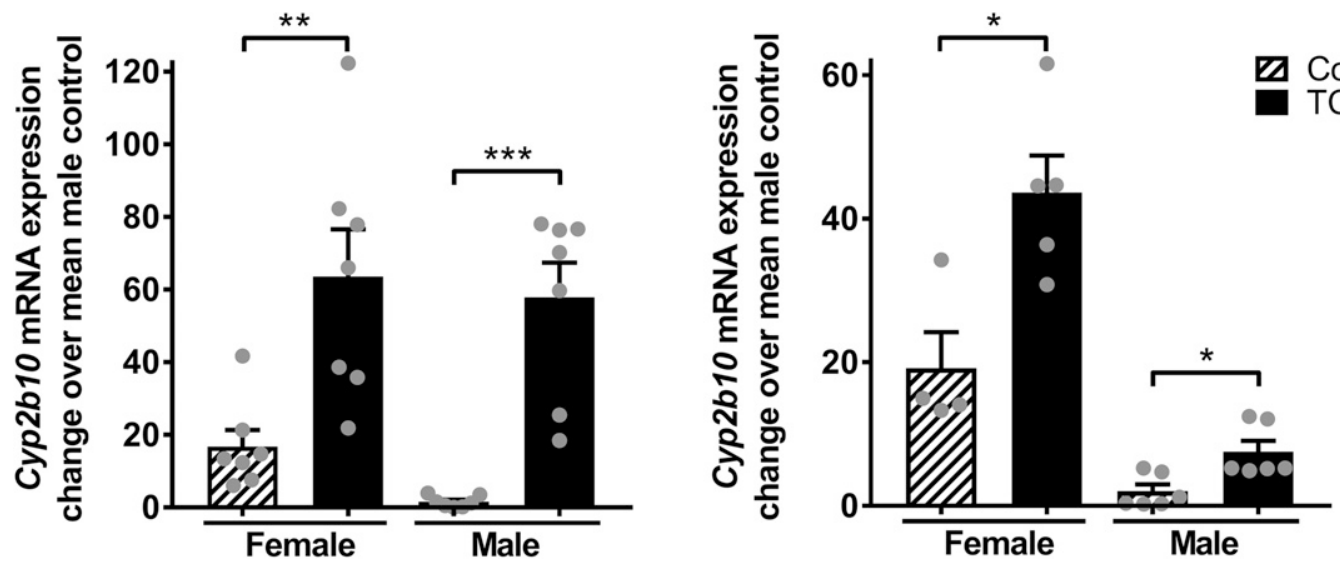

Fig. 1. Cyp2b10 induction in the F1 offspring driven by a single maternal, preconceptional TCPOBOP injection. Hepatic Cyp2b10 mRNA expression was determined by real-time polymerase chain reaction and $\Delta \Delta \mathrm{Ct}$-method. Adult (A and B) or 3-day-old (C) female F0 mice were injected intraperitoneally with TCPOBOP (3 mg/kg) in corn oil or with corn oil alone. Cyp2b10 expression in F1 mice was assessed 6 days (A), 8 (B), or 12-weeks (C) after birth. Data are presented as mean fold-expression changes \pm S.E.M. over the mean male corn oil group $(n=4-10)$, which were analyzed by $t$ test or Mann-Whitney test. Statistically significant differences are indicated by asterisks $(* * * P<0.001 ; * P<0.05)$. (A) (right panel) Western blot of hepatic CYP2B10 expression of four male 6-day-old F1 mice born from females injected with TCPOBOP or with corn oil 1 week prior to mating. GAPDH expression served as a loading control.

F0 females. Alternatively, it could occur post-conceptionally, either by placenta- or feeding-mediated (via milk) TCPOBOP transfer to the $\mathrm{F} 1$ offspring. To distinguish between these possibilities, we conducted embryo transfer experiments. F1 mice conceived by untreated females,

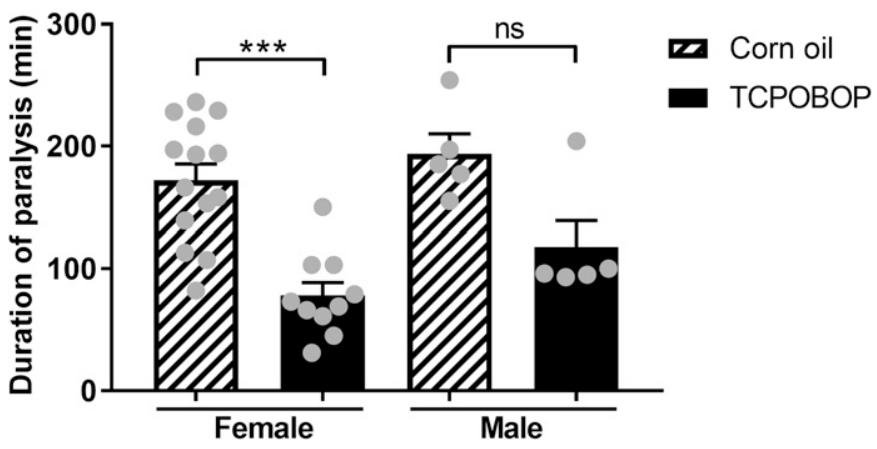

Fig. 2. Effects of F0 TCPOBOP treatment on the zoxazolamine-induced paralysis in $\mathrm{F} 1$ mice. Female F0 mice were injected with TCPOBOP $(3 \mathrm{mg} / \mathrm{kg})$ in corn oil or with corn oil alone 1 week prior to mating with untreated males. Shown is the duration of zoxazolamine $(175 \mathrm{mg} / \mathrm{kg}$, i.p.)-induced paralysis time in 8 -week-old F1 offspring. Data are presented as mean \pm S.E.M. $(n=5-14)$ and were analyzed by $t$ test. Statistically significant differences are indicated by asterisks $(* * * P<0.001)$. but carried to term by foster mothers pretreated with TCPOBOP, exhibited increased Cyp 2 b10 expression. In contrast, F1 mice conceived by TCPOBOP-pretreated donor mice, but carried to term by untreated foster mothers, showed no increase in Cyp2b10 expression (Fig. 4A). Both of these results suggested a post- rather than preconceptional mechanism of induction transmission.

To differentiate between a transplacental (in utero) and a milk-mediated (postnatal) TCPOBOP transfer, we conducted crossfostering experiments (Fig. 4B). E19.5 F1 offspring of corn oil-treated mice transferred to TCPOBOP-pretreated foster mothers showed $82 \%$ of the Cyp $2 b 10$ induction measured in $\mathrm{E} 19.5 \mathrm{~F} 1$ offspring of TCPOBOP-treated mice transferred to TCPOBOP-pretreated foster mothers. Conversely, E19.5 F1 offspring of TCPOBOP-treated mice transferred to corn oil-injected foster mothers showed $1 \%$ of the Cyp $2 b 10$ induction measured in E19.5 F1 offspring of TCPOBOP-treated mice transferred to TCPOBOP-pretreated foster mothers. These results indicated that a vast majority of the induction occurs via postnatal TCPOBOP transmission. This was confirmed additionally by injecting lactating females with TCPOBOP at different time points $(5,10$, or 15 days) after they had given birth. Cyp2b10 expression strongly increased in the F1 mice suckling for 3 days after the injection of F0 mothers, as well as in 60-day-old F1 mice, i.e., 6 weeks after weaning 
A

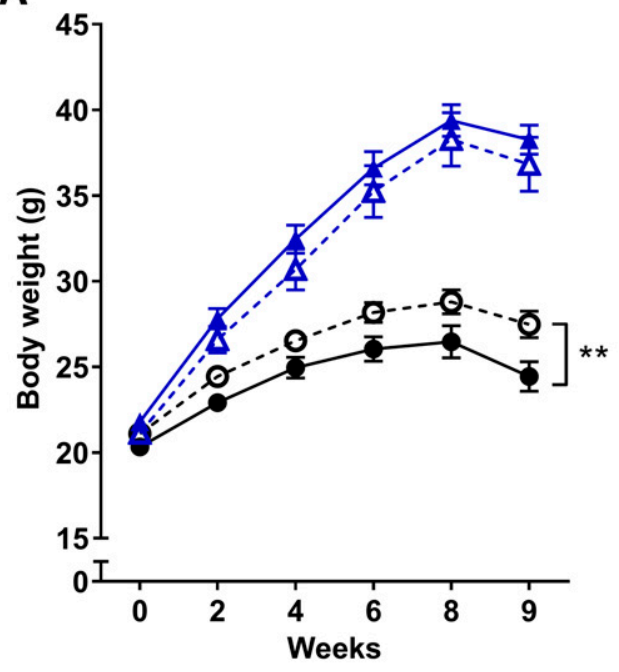

๑. Corn oil standard die

TCPOBOP standard diet

C

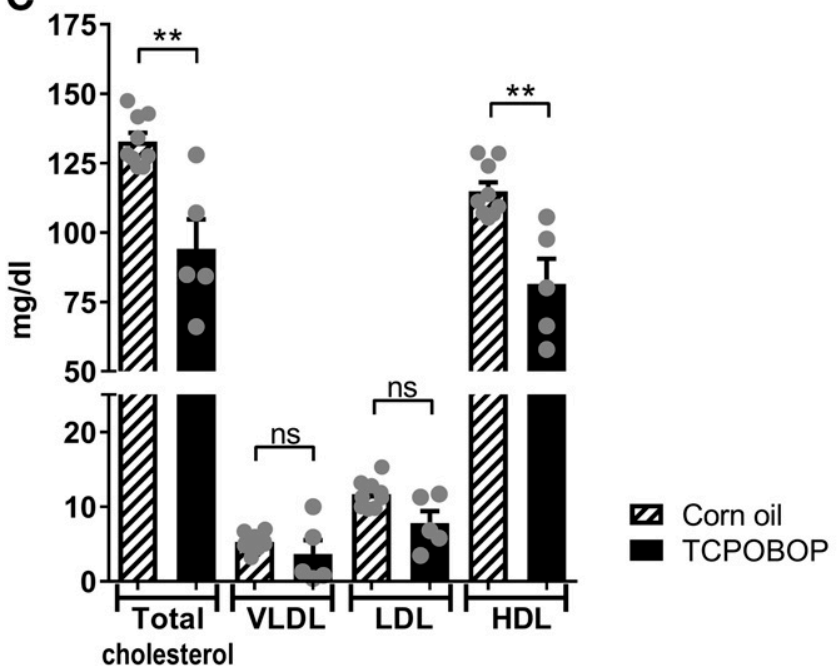

(females Fig. 5, males Supplemental Fig. 7). After weaning of F1 offspring, the Cyp2b10 expression in TCPOBOP-pretreated mothers returned to the level of mothers pretreated with corn oil (Supplemental Fig. 8).

These results suggested a lactation-mediated transfer of TCPOBOP to F1 offspring, which was confirmed by HPLC-MS/MS analysis of $\mathrm{F} 0$ and $\mathrm{F} 1$ adipose tissue. The concentration of TCPOBOP, injected in adult $\mathrm{F} 0$ females at a dose of $3 \mathrm{mg} / \mathrm{kg}$, was stable in F0 adipose tissue over a period of at least 12 weeks (Fig. 6A, lanes 2 and 9). The TCPOBOP concentration in the adipose tissue of 12 -week-old F1 offspring of females induced 1 week prior to mating was 160 -fold lower (Fig. 6A, lane 11). The TCPOBOP concentration in the adipose tissue of F1 offspring was thus like that observed in F0 females injected with 100to 500-times smaller amounts of TCPOBOP (Fig. 6A, lanes 5 and 6). The magnitude of $C y p 2 b 10$ induction in the $\mathrm{F} 1$ generation corresponded to that following 1/10th to 1/100th of the original dose given to F0 (Fig. $6 \mathrm{~B}$, lane 4, 5 and 11). Taken together, these results demonstrated that TCPOBOP is transmitted to F1 and that its amount determines the amplitude of Cyp $2 b 10$ induction.

Transmission to F1 May Require Lipophilicity. Since TCPOBOP is lipophilic, we hypothesized that induction transmission would be a general property of lipophilic compounds. To provide a first verification, we used the lipophilic environmental pollutant and CAR inducer PCB153 (Gahrs et al., 2013; Wahlang et al., 2014). One week after treatment with $100 \mathrm{mg} / \mathrm{kg}$ PCB153, adult female mice were mated with untreated males. Cyp 2 b 10 expression was induced 820 -fold in female and 700-fold in male 6-day-old F1 offspring compared with the respective corn oil controls (Fig. 7). We then compared PCB153 with the hydrophilic CAR inducer phenobarbital. Newborn female F0 mice injected once intraperitoneally with $100 \mathrm{mg} / \mathrm{kg}$ phenobarbital showed a 70- and 200-fold Cyp2b10 induction after 24 hours in females and males, respectively. Six weeks later, the induction declined to 3.3-fold in females and 1.6-fold in males (Supplemental Fig. 9A). Newborn F1 offspring of these phenobarbital-treated mice showed no Cyp $2 b 10$ induction (Supplemental Fig. 9B).

\section{Discussion}

We demonstrate that long lasting, lipophilic chemicals applied far ahead of pregnancy are transmitted via milk and evoke health-relevant phenotypes in the adult F1 offspring. We show it for two ligands of the xenosensing nuclear receptor CAR, but the mechanism probably applies to any other receptor modifiable by lipophilic chemicals. The resulting 
A

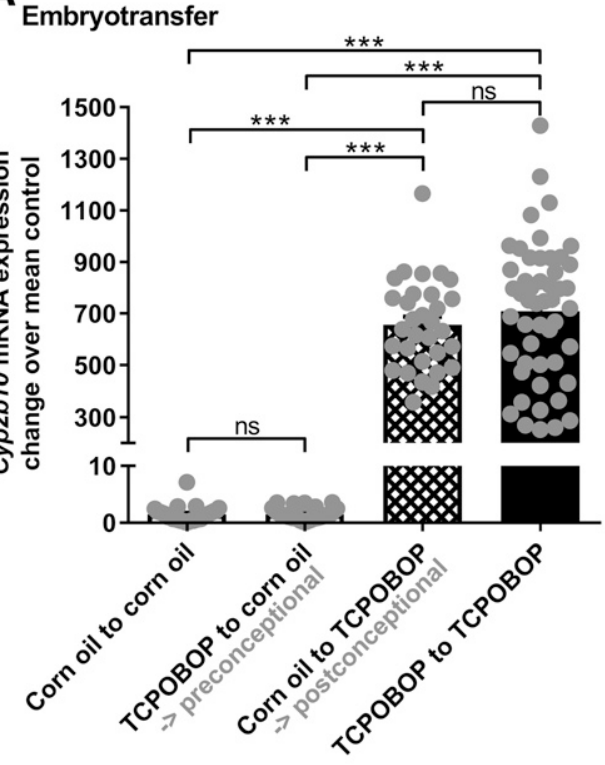

B

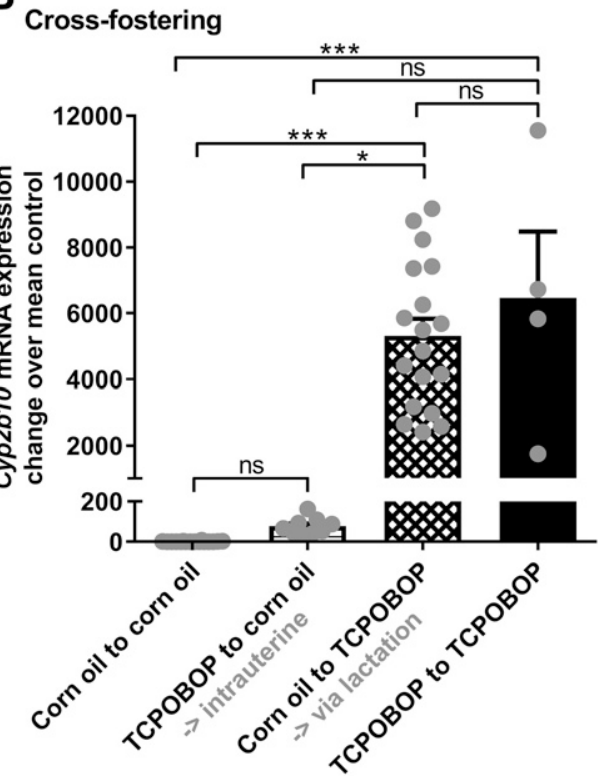

Fig. 4. Cyp $2 b 10$ mRNA expression in the embryo-transferred or crossfostered F1 offspring. (A) Embryo transfer: Donor C57BL/6J females were injected with TCPOBOP $(3 \mathrm{mg} / \mathrm{kg})$ in corn oil or with corn oil alone and super-ovulated and mated with untreated males 3 weeks later. Twocell embryos were transferred to CD1 recipients pretreated 1 week earlier with ТСРОВОР $(3 \mathrm{mg} / \mathrm{kg})$ in corn oil or with corn oil alone, and carried to term $(n=29-50)$. (B) Crossfostering: C57BL/6J and $\mathrm{CD} 1$ females were injected with TCPOBOP ( $3 \mathrm{mg} / \mathrm{kg}$ ) in corn oil or with corn oil alone, and mated with untreated males 1 week later. Following cesarian section on gestational day 19.5, F1 C57BL/6J offspring mice $(n=4-18)$ were substituted for up to $50 \%$ of litters nursed by CD1 mice. The hepatic Cyp2b10 mRNA expression was determined in 6-day-old F1 animals by real-time polymerase chain reaction and $\Delta \Delta$ Ct-method and was analyzed by KruskalWallis test and Dunn's post hoc-test. Statistically significant differences over the control "corn oil to corn oil" are indicated by asterisks $(* * * P<0.001 ; * P<0.05)$. Data are presented as mean \pm S.E.M.
F1 phenotypes include subtle changes of energy and drug metabolism, which may manifest clinically only later in life, or under specific conditions such as drug treatments. Owing to long-term accumulation in adipose tissue, the ligand transmission to F1, exemplified by TCPOBOP, takes place even if the treatment has been terminated far ahead of conception. These findings are of importance for the management of chemicals released into the environment, for the development of new drugs, and for planning and management of pregnancies.

Mechanism. The latest literature suggests that persistent epigenetic changes in the promoters of CAR target genes, including Cyp 2 b10, are responsible for prolonged induction within the $\mathrm{F} 0$ generation in the liver (Chen et al., 2012; Peng and Zhong, 2015; Tien et al., 2015, 2017; Li et al., 2016; Piekos et al., 2017; Lodato et al., 2018). Our work indicates that at least some of these effects may have been driven by activator accumulation rather than by stable DNA modifications.

The involvement of a physical ligand transfer in the induction transmission is supported by the detection in F1 of TCPOBOP (this study) and of PCB153 (Gallenberg and Vodicnik, 1987; Ring et al., 1990). It is also consistent with the long-term accumulation of these compounds in F0 adipose tissue (Poland et al., 1980; Gallenberg and Vodicnik, 1987; Gallenberg et al., 1990; Ring et al., 1990; Smith et al., 1993), confirmed in this study. Adipose tissue undergoes mobilization upon lactation
(Lederman, 2004). The resulting TCPOBOP transfer to $\mathrm{F} 1$ is in accordance with the absence of Cyp $2 b 10$ induction in mothers after weaning. The mobilization also reduces the PCB153 burden in F0 mothers, just as the chemical becomes detectable in the F1 offspring (Gallenberg and Vodicnik, 1987). Milk is the main vehicle of transmission, as demonstrated previously for PCB153 (Gallenberg and Vodicnik, 1987) and in this study for TCPOBOP. Accordingly, we found a nearly maximal Cyp $2 b 10$ induction in cesarian section-delivered F1 offspring of TCPOBOP-naïve mothers transferred to TCPOBOP pretreated foster (i.e., lactating) mothers. Induction also occurred upon injection of lactating females with TCPOBOP. Significantly, PCB153 has been found in human breast milk samples (Lignell et al., 2009).

In comparison with the amounts of TCPOBOP transferred via milk, the transplacental transmission was minimal, judging from the negligible induction in F1 offspring of TCPOBOP-treated females transferred to TCPOBOP-naïve foster mothers for lactation. Likewise, PCB153 does not cross the placenta, which has been attributed to the strong binding to VLDL (Gallenberg and Vodicnik, 1987). TCPOBOP transfer via fur licking could not have contributed to induction transmission, since allogrooming starts only several days after our time point of F1 induction analysis (Williams and Scott, 1953; Fox, 1965). We excluded the possibility of preconceptional "imprinting" of induction by TCPOBOP
A

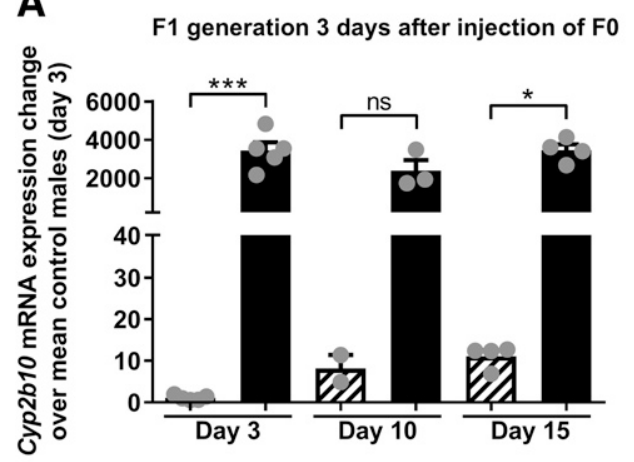

B

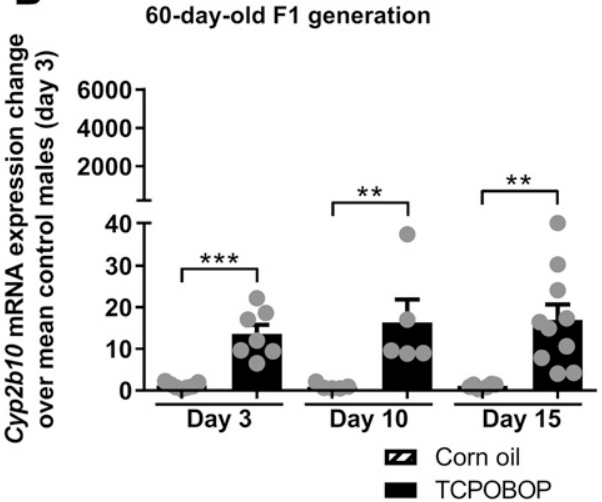

Fig. 5. TCPOBOP transfer via lactation initiated at three time points after birth. Lactating F0 females were treated with TCPOBOP on day 3,10 , or 15 after giving birth. Hepatic Cyp2b10 mRNA expression was analyzed in female F1 newborns 3 days after maternal TCPOBOP treatment, $n=2-5$ (A) or in 60-dayold female F1 mice, $n=5-10$ (B). Shown are mean expression changes over mean male controls \pm S.E.M. determined by real-time polymerase chain reaction and $\Delta \Delta \mathrm{Ct}$-method, which were analyzed by $t$ test or Mann-Whitney test. Statistically significant differences are indicated by asterisks $(* * * P<0.001 ; * * P<$ $0.01 ; * P<0.05$ ). Similar results were obtained for male offspring (Supplemental Fig. 7). 
A ТСРОвОР concentration in adipose tissue

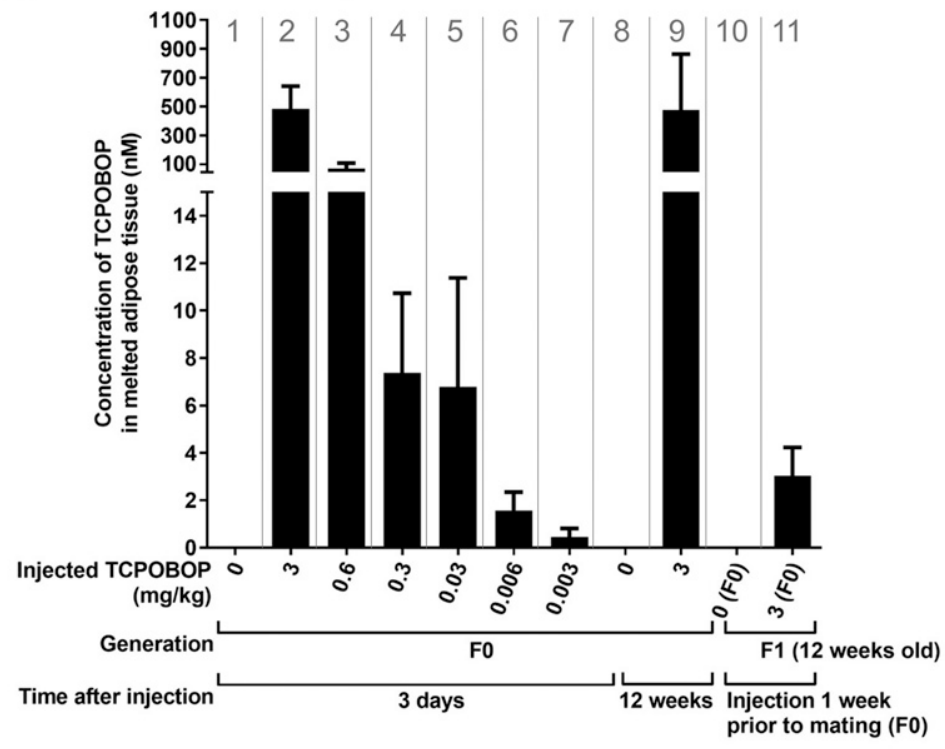

B Hepatic Cyp2b10 mRNA expression

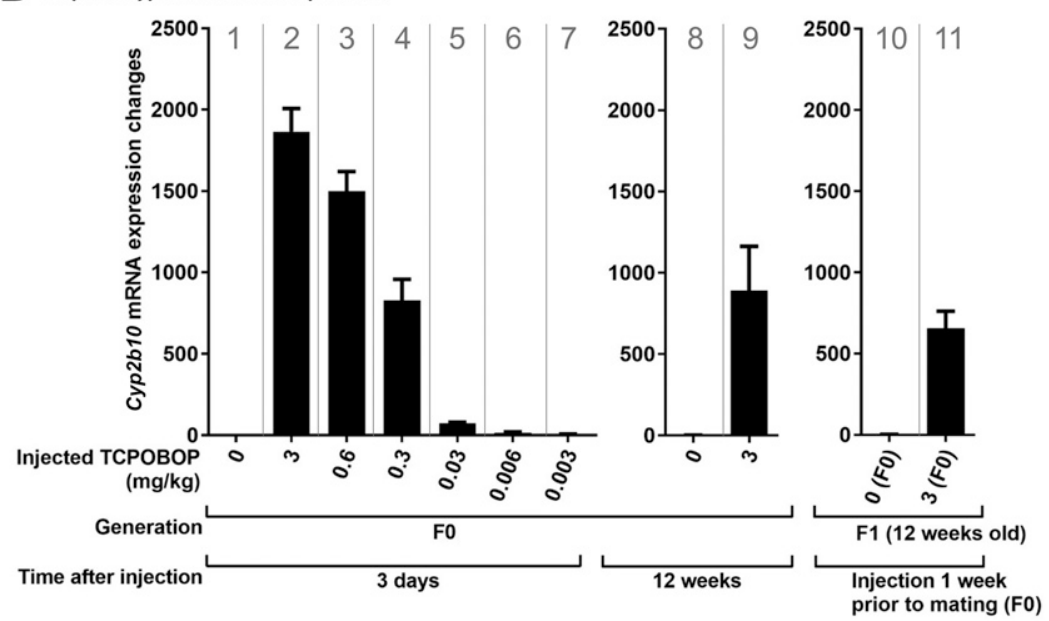

Fig. 6. ТСРОВОР concentrations in the adipose tissue and the corresponding hepatic Cyp2b10 induction. (A) TCPOBOP was detected by HPLC-MS/MS. TCPOBOP was extracted from $120 \mu \mathrm{l}$ of melted epididymal adipose tissue of mice treated at the age of 11 weeks with different TCPOBOP concentrations $(0,3,0.6,0.3$, $0.03,0.006,0.003 \mathrm{mg} / \mathrm{kg}$ ) 3 days prior to analysis, and with $3 \mathrm{mg} / \mathrm{kg} 12$ weeks prior to analysis. F1 offspring of F0 female mice injected with ТСРОВOP $(3 \mathrm{mg} / \mathrm{kg})$ and mated 1 week later were analyzed 12 weeks after birth. Shown are mean TCPOBOP concentrations \pm S.E.M. $(n=4)$. (B) Cyp $2 b 10$ mRNA expression changes over the respective time point- and generation-mated, corn oil-injected controls in livers of mice shown in (A) was determined by real-time polymerase chain reaction and $\Delta \Delta \mathrm{Ct}$-method. Data are presented as mean expression fold-changes \pm S.E.M. by embryo transfer experiments, and we did not detect any effects in F1 following the less lipophilic phenobarbital.

Nongenetic transfer of phenotypes originating from a treatment prior to pregnancy has been attributed to epigenetic marks in the gametes (Anway et al., 2005), to somatic reprogramming following in utero exposure (Iqbal et al., 2015), or to RNA transfer via sperm cells (Rodgers et al., 2015). Our work demonstrates that such phenotypes may arise via accumulation of chemicals and their transfer to the next generation. The possible routes are placenta (Jeong et al., 2018), seminal fluid (Bromfield et al., 2014), and milk, as demonstrated here using a specific ligand-receptor pair.

Metabolic Effects. The CYP2B10 induction in the F1 generation decreased efficacy of the muscle relaxant zoxazolamine. The transcriptional targets of human CAR, CYP2B6, CYP3A4, and UGT1A1, (Park et al., 2016) metabolize a majority of clinically used drugs, including antineoplastics, anesthetics, opioids, and antiretrovirals (Wang and Tompkins, 2008; Hedrich et al., 2016). It is tempting to speculate that long-lasting CAR ligands are responsible for interindividual expression variability of these targets that cannot be explained by genetic variants (Zanger et al., 2001; Peng and Zhong, 2015; Hedrich et al., 2016), although further experiments are needed to validate this hypothesis.
This variability further complicates drug dose finding, especially in newborns, or may cause toxicities (Tayman et al., 2011; Pauwels and Allegaert, 2016).

TCPOBOP-mediated effects on F1 energy metabolism included a reduction in body weight gain, improved glucose tolerance during highfat diet, and reduced serum lipids. They are consistent with a protective role of CAR induction against metabolic syndrome-like phenotypes in F0 (Gao et al., 2009; Kobayashi et al., 2015). The reduction of body weight gain in F0 and F1 was independent of food intake, supporting the previously reported higher energy expenditure upon CAR activation in brown adipose tissue (Gao et al., 2009). The observed F1 phenotypes match those in F0 animals in terms of directionality. The subtle differences most probably result from lower exposure of the F1 to TCPOBOP compared with the F0.

The phenotypes were in line with transcriptomic changes. Besides drug metabolism, TCPOBOP affected regulators of pathways involved in the energy homeostasis of newborn and adult F0 mice as well as newborn and adult F1 mice. PPAR $\alpha$, FXR, and LXR have an impact on energy metabolism and the pathogenesis of fatty liver disease (Kersten and Stienstra, 2017; Li et al., 2017; Tanaka et al., 2017). IL6 plays a role in type 2 diabetes (Phosat et al., 2017) and HNF4A in hereditary diabetes 


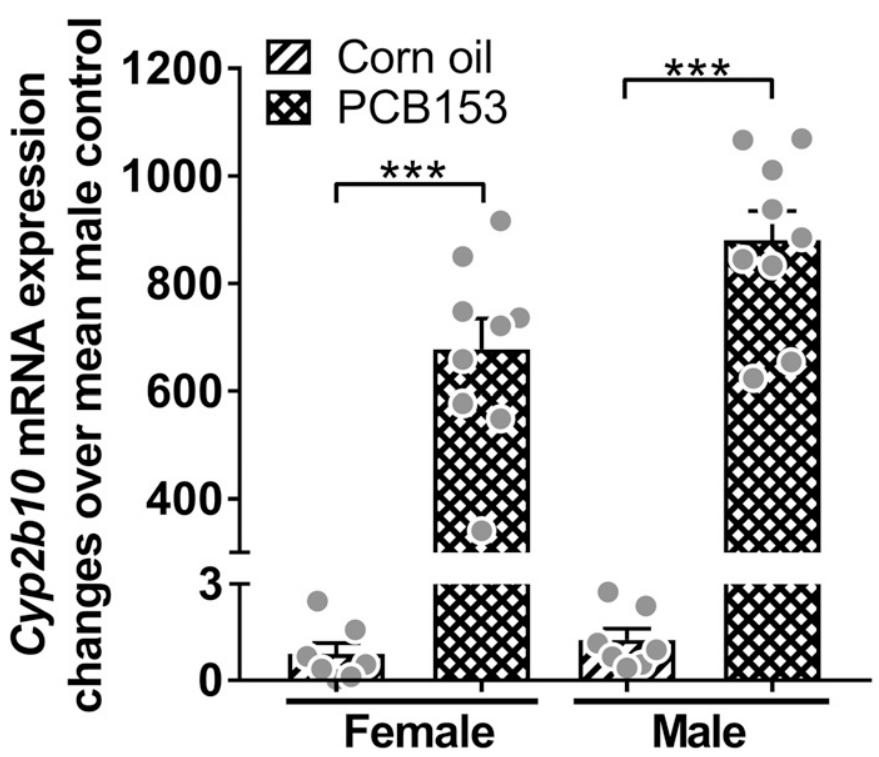

Fig. 7. Cyp2b10 induction in the F1-generation by PCB153. Seven-week-old adult F0 female mice were injected once with PCB153 (100 mg/kg) or vehicle (corn oil). After 1 week, they were mated with untreated males. Cyp2b10 expression was assessed in 6-day-old F1 offspring. Shown are mean expression changes over the mean of male controls \pm S.E.M. determined by real-time polymerase chain reaction and $\Delta \Delta$ Ct-method and analyzed by $t$ test. Statistically significant differences are indicated by asterisks $(* * * P<0.001)$.

(Yamagata et al., 1996). Nrf2 is involved in glucose resistance and dyslipidemia (Xu et al., 2015; Zhang et al., 2015b). Lipid metabolism was one of the top three regulated pathways 60 days after TCPOBOP treatment of F0 animals in a previous study ( $\mathrm{Li}$ et al., 2016).

Significance for Chemical Safety and Pregnancy Management. Termination of therapy 6-24 months ahead of pregnancy is presently recommended only for a handful of long-term accumulating drugs, including cytostatics, radioiodine, vitamin $\mathrm{K}$ antagonists, amiodarone, leflunomide, methotrexate, and retinoids. These drugs are either teratogenic or they cause adverse effects manifesting immediately after birth, exemplified by hypothyroidism after amiodarone (Magee et al., 1995).

Our work strongly suggests that these recommendations should be expanded to other drugs and extended to the avoidance of certain environmental chemicals. Indeed, long-term accumulating chemicals, exemplified here by TCPOBOP and PCB153 (Schecter et al., 2010; Whitehead et al., 2013; Pozo et al., 2017), may be transmitted to F1 and induce health-relevant phenotypes even if treatment has been terminated far ahead of conception. Such phenotypes may remain undetected, since developmental toxicology currently focuses on teratogenic effects. These phenotypes are more subtle and manifest later in life. It is probable that such unapparent phenotypes arise in F1 after the transmission of lipophilic ligands of other receptors. This could and should be assessed for both approved and investigational drugs and chemicals known or suspected of accumulation in adipose tissue.

Such drugs and chemicals can be identified by a combination of small molecular weight, high logarithmic partition coefficient $(\log \mathrm{P})$, and logarithmic acid dissociation constant (pKa) $<7$ (Moor et al., 1992), which also correlate with the probability of transfer via milk (Howard and Lawrence, 2001; Kar and Roy, 2013). Highly lipophilc drugs $(\log \mathrm{P}>6)$ include the CAR ligand atorvastatin (Režen et al., 2017), as well as montelukast, raloxifene, cinacalcet, fexofenadine, repaglinide, telmisartan, adapalene, terbinafine, dutasteride, and levothyroxine (Zhong et al., 2013). Many common environmental pollutants are lipophilic $(\log \mathrm{P}>3)$ CAR ligands [e.g., DDT (Kamata et al., 2018), permethrin
(Kublbeck et al., 2011), chlordane (Kamata et al., 2018), dibutylphthalate (Wyde et al., 2005), dieldrin (Wei et al., 2002), methoxychlor (Kamata et al., 2018), pyren (Zhang et al., 2015a), and toxaphen (Wei et al., 2002)], which cross the placenta or are transferred via milk (Campoy et al., 2001; Skopp et al., 2002; Cok et al., 2012; Corcellas et al., 2012; Limon-Miro et al., 2017; Muller et al., 2017; Wang et al., 2017; Yasmeen et al., 2017). The lipophilic pollutants and CAR modulators BPA and DEHP (DeKeyser et al., 2011) exhibit not only multi- but even transgenerational (beyond F1) effects (Ziv-Gal et al., 2015; Pocar et al., 2017). The assessment of F1 effects could start with transcriptional profiling in appropriate animal models.

\section{Acknowledgments}

We thank Dr. M. Michel (Department of Pharmacology, University Medical Center Mainz), Drs. F. Colbatzky and R. Kaiser (Boehringer Ingelheim Pharma $\mathrm{GmbH} \& \mathrm{Co} . \mathrm{KG}$ ) for comments to the manuscript. We gratefully acknowledge the computing time granted on the supercomputer Mogon at Johannes Gutenberg University Mainz (hpc.uni-mainz.de).

\section{Authorship Contributions}

Participated in research design: Dietrich, Baumgart, Eshkind, Butt, Musheev, Niehrs, Wojnowski, Mathäs.

Conducted experiments: Dietrich, Baumgart, Eshkind, Reuter, Gödtel-Armbrust, Butt, Musheev, Grosser, Mathäs.

Contributed new reagents or analytic tools: Butt, Musheev, Niehrs. Performed data analysis: Dietrich, Butt, Musheev, Marini, More, Mathäs. Wrote or contributed to the writing of the manuscript: Wojnowski, Mathäs.

\section{References}

Abdul-Ghani S, Yanai J, Abdul-Ghani R, Pinkas A, and Abdeen Z (2012) The teratogenicity and behavioral teratogenicity of di(2-ethylhexyl) phthalate (DEHP) and di-butyl phthalate (DBP) in a chick model. Neurotoxicol Teratol 34:56-62.

Anway MD, Cupp AS, Uzumcu M, and Skinner MK (2005) Epigenetic transgenerational actions of endocrine disruptors and male fertility. Science 308:1466-1469.

Ayala JE, Samuel VT, Morton GJ, Obici S, Croniger CM, Shulman GI, Wasserman DH, and McGuinness OP; NIH Mouse Metabolic Phenotyping Center Consortium (2010) Standard operating procedures for describing and performing metabolic tests of glucose homeostasis in mice. Dis Model Mech 3:525-534.

Barrett T, Wilhite SE, Ledoux P, Evangelista C, Kim IF, Tomashevsky M, Marshall KA, Phillippy KH, Sherman PM, Holko M, et al. (2013) NCBI GEO: archive for functional genomics data sets--update. Nucleic Acids Res 41:D991-D995.

Bates D, Machler M, Bolker BM, and Walker SC (2015) Fitting linear mixed-effects models using lme4. J Stat Softw 67:1-48.

Bromfield JJ, Schjenken JE, Chin PY, Care AS, Jasper MJ, and Robertson SA (2014) Materna tract factors contribute to paternal seminal fluid impact on metabolic phenotype in offspring. Proc Natl Acad Sci USA 111:2200-2205.

Campoy C, Jiménez M, Olea-Serrano MF, Moreno-Frías M, Cañabate F, Olea N, Bayés R, and Molina-Font JA (2001) Analysis of organochlorine pesticides in human milk: preliminary results. Early Hum Dev 65 (Suppl):S183-S190.

Chen WD, Fu X, Dong B, Wang YD, Shiah S, Moore DD, and Huang W (2012) Neonatal activation of the nuclear receptor CAR results in epigenetic memory and permanent change of drug metabolism in mouse liver. Hepatology 56:1499-1509.

Çok I, Mazmanci B, Mazmanci MA, Turgut C, Henkelmann B, and Schramm KW (2012) Analysis of human milk to assess exposure to PAHs, PCBs and organochlorine pesticides in the vicinity Mediterranean city Mersin, Turkey. Environ Int 40:63-69.

Corcellas C, Feo ML, Torres JP, Malm O, Ocampo-Duque W, Eljarrat E, and Barceló D (2012) Pyrethroids in human breast milk: occurrence and nursing daily intake estimation. Environ In 47:17-22.

Couture LA, Abbott BD, and Birnbaum LS (1990) A critical review of the developmental toxicity and teratogenicity of 2,3,7,8-tetrachlorodibenzo-p-dioxin: recent advances toward understanding the mechanism. Teratology 42:619-627.

DeKeyser JG, Laurenzana EM, Peterson EC, Chen T, and Omiecinski CJ (2011) Selective phthalate activation of naturally occurring human constitutive androstane receptor splice variants and the pregnane X receptor. Toxicol Sci 120:381-391.

Dobin A, Davis CA, Schlesinger F, Drenkow J, Zaleski C, Jha S, Batut P, Chaisson M, and Gingeras TR (2013) STAR: ultrafast universal RNA-seq aligner. Bioinformatics 29:15-21.

Edgar R, Domrachev M, and Lash AE (2002) Gene Expression Omnibus: NCBI gene expression and hybridization array data repository. Nucleic Acids Res 30:207-210.

Fox WM (1965) Reflex-ontogeny and behavioural development of the mouse. Anim Behav 13 234-241.

Gährs M, Roos R, Andersson PL, and Schrenk D (2013) Role of the nuclear xenobiotic receptors CAR and PXR in induction of cytochromes P450 by non-dioxinlike polychlorinated biphenyls in cultured rat hepatocytes. Toxicol Appl Pharmacol 272:77-85.

Gallenberg LA, Ring BJ, and Vodicnik MJ (1990) The influence of time of maternal exposure to $2,4,5,2^{\prime}, 4^{\prime}, 5^{\prime}$-hexachlorobiphenyl on its accumulation in their nursing offspring. Toxicol Appl Pharmacol 104:1-8.

Gallenberg LA and Vodicnik MJ (1987) Potential mechanisms for redistribution of polychlorinated biphenyls during pregnancy and lactation. Xenobiotica 17:299-310. 
Gao J, He J, Zhai Y, Wada T, and Xie W (2009) The constitutive androstane receptor is an antiobesity nuclear receptor that improves insulin sensitivity. J Biol Chem 284:25984-25992.

Gil-Pulido J, Cochain C, Lippert MA, Schneider N, Butt E, Amézaga N, and Zernecke A (2017) Deletion of Batf3-dependent antigen-presenting cells does not affect atherosclerotic lesion formation in mice. PLoS One 12:e181947.

Heard E and Martienssen RA (2014) Transgenerational epigenetic inheritance: myths and mechanisms. Cell 157:95-109.

Hedrich WD, Hassan HE, and Wang H (2016) Insights into CYP2B6-mediated drug-drug interactions. Acta Pharm Sin B 6:413-425.

Howard CR and Lawrence RA (2001) Xenobiotics and breastfeeding. Pediatr Clin North Am 48 485-504.

Hughes V (2014) Epigenetics: the sins of the father. Nature 507:22-24.

Iqbal K, Tran DA, Li AX, Warden C, Bai AY, Singh P, Wu X, Pfeifer GP, and Szabó PE (2015) Deleterious effects of endocrine disruptors are corrected in the mammalian germline by epigenome reprogramming. Genome Biol 16:59.

Jeong Y, Lee S, Kim S, Park J, Kim HJ, Choi G, Choi S, Kim S, Kim SY, Kim S, et al. (2018) Placental transfer of persistent organic pollutants and feasibility using the placenta as a noninvasive biomonitoring matrix. Sci Total Environ 612:1498-1505.

Kamata R, Nakajima D, and Shiraishi F (2018) Agonistic effects of diverse xenobiotics on the constitutive androstane receptor as detected in a recombinant yeast-cell assay. Toxicol In Vitro 46:335-349.

Kar S and Roy K (2013) Prediction of milk/plasma concentration ratios of drugs and environmental pollutants using in silico tools: classification and regression based QSARs and pharmacophore mapping. Mol Inform 32:693-705.

Kersten S and Stienstra R (2017) The role and regulation of the peroxisome proliferator activated receptor alpha in human liver. Biochimie 136:75-84.

Kobayashi K, Hashimoto M, Honkakoski P, and Negishi M (2015) Regulation of gene expression by CAR: an update. Arch Toxicol 89:1045-1055.

Küblbeck J, Laitinen T, Jyrkkärinne J, Rousu T, Tolonen A, Abel T, Kortelainen T, Uusitalo J, Korjamo T, Honkakoski P, et al. (2011) Use of comprehensive screening methods to detect selective human CAR activators. Biochem Pharmacol 82:1994-2007.

Lederman SA (2004) Influence of lactation on body weight regulation. Nutr Rev 62:S112-S119.

Li CY, Cheng SL, Bammler TK, and Cui JY (2016) Editor's highlight: neonatal activation of the xenobiotic-sensors PXR and CAR results in acute and persistent down-regulation of PPARalphasignaling in mouse liver. Toxicol Sci 153:282-302.

Li G, Brocker CN, Xie C, Yan T, Noguchi A, Krausz KW, Xiang R, and Gonzalez FJ (2017) Hepatic PPARalpha mediates the major metabolic effects of Wy-14643. J Gastroenterol Hepatol 33:1138-1145.

Lignell S, Aune M, Darnerud PO, Cnattingius S, and Glynn A (2009) Persistent organochlorine and organobromine compounds in mother's milk from Sweden 1996-2006: compound-specific temporal trends. Environ Res 109:760-767.

Limon-Miro AT, Aldana-Madrid ML, Alvarez-Hernandez G, Antunez-Roman LE, RodriguezOlibarria G, and Valencia Juillerat ME (2017) Breast milk intake and mother to infant pesticide transfer measured by deuterium oxide dilution in agricultural and urban areas of Mexico. Chemosphere 181:682-689.

Livak KJ and Schmittgen TD (2001) Analysis of relative gene expression data using real-time quantitative PCR and the 2(-Delta Delta C(T)) Method. Methods 25:402-408.

Lodato NJ, Rampersaud A, and Waxman DJ (2018) Impact of CAR agonist ligand TCPOBOP on mouse liver chromatin accessibility. Toxicol Sci 164:115-128.

Magee LA, Downar E, Sermer M, Boulton BC, Allen LC, and Koren G (1995) Pregnancy outcome after gestational exposure to amiodarone in Canada. Am J Obstet Gynecol 172:1307-1311.

Moor MJ, Steiner SH, Jachertz G, and Bickel MH (1992) Adipose tissue distribution and chemical structure of basic lipophilic drugs: desipramine, $\mathrm{N}$-acetyl desipramine, and haloperidol. Pharmacol Toxicol 70:121-124.

Moreau A, Vilarem MJ, Maurel P, and Pascussi JM (2008) Xenoreceptors CAR and PXR activation and consequences on lipid metabolism, glucose homeostasis, and inflammatory response. Mol Pharm 5:35-41.

Müller MHB, Polder A, Brynildsrud OB, Karimi M, Lie E, Manyilizu WB, Mdegela RH, Mokiti F, Murtadha M, Nonga HE, et al. (2017) Organochlorine pesticides (OCPs) and polychlorinated biphenyls (PCBs) in human breast milk and associated health risks to nursing infants in Northern Tanzania. Environ Res 154:425-434.

Parini P, Johansson L, Bröijersén A, Angelin B, and Rudling M (2006) Lipoprotein profiles in plasma and interstitial fluid analyzed with an automated gel-filtration system. Eur J Clin Inves 36: $98-104$.

Park S, Cheng SL, and Cui JY (2016) Characterizing drug-metabolizing enzymes and transporters that are bona fide CAR-target genes in mouse intestine. Acta Pharm Sin B 6:475-491

Pauwels S and Allegaert K (2016) Therapeutic drug monitoring in neonates. Arch Dis Child 101: 377-381.

Peng L and Zhong X (2015) Epigenetic regulation of drug metabolism and transport. Acta Pharm Sin B 5:106-112.

Phosat C, Panprathip P, Chumpathat N, Prangthip P, Chantratita N, Soonthornworasiri N, Puduang S, and Kwanbunjan K (2017) Elevated C-reactive protein, interleukin 6, tumor necrosis factor alpha and glycemic load associated with type 2 diabetes mellitus in rural Thais: a cross-sectional study. BMC Endocr Disord 17:44.

Piekos S, Pope C, Ferrara A, and Zhong XB (2017) Impact of drug treatment at neonatal ages on variability of drug metabolism and drug-drug interactions in adult life. Curr Pharmacol Rep 3:1-9.

Pocar P, Fiandanese N, Berrini A, Secchi C, and Borromeo V (2017) Maternal exposure to di(2ethylhexyl)phthalate (DEHP) promotes the transgenerational inheritance of adult-onset reproductive dysfunctions through the female germline in mice. Toxicol Appl Pharmacol 322:113-121.

Poland A, Mak I, Glover E, Boatman RJ, Ebetino FH, and Kende AS (1980) 1,4-Bis[2-(3,5dichloropyridyloxy)]benzene, a potent phenobarbital-like inducer of microsomal monooxygenase activity. Mol Pharmacol 18:571-580.

Pozo K, Oyola G, Estellano VH, Harner T, Rudolph A, Prybilova P, Kukucka P, Audi O, Klánová J, Metzdorff A, et al. (2017) Persistent Organic Pollutants (POPs) in the atmosphere of three Chilean cities using passive air samplers. Sci Total Environ 586:107-114.

Prakash C, Zuniga B, Song CS, Jiang S, Cropper J, Park S, and Chatterjee B (2015) Nuclear receptors in drug metabolism, drug response and drug interactions. Nucl Receptor Res 2:101178.

R Core Team (2017) R: A Language and Environment for Statistical Computing, R Foundation for Statistical Computing, Vienna, Austria.
Režen T, Hafner M, Kortagere S, Ekins S, Hodnik V, and Rozman D (2017) Rosuvastatin and atorvastatin are ligands of the human constitutive androstane receptor/retinoid X receptor $a$ complex. Drug Metab Dispos 45:974-976.

Ring BJ, Seitz KR, Gallenberg LA, and Vodicnik MJ (1990) The effect of diet and litter size on the

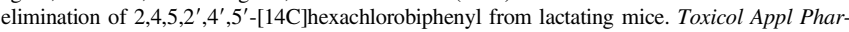
macol 104:9-16.

Robinson MD, McCarthy DJ, and Smyth GK (2010) edgeR: a Bioconductor package for differential expression analysis of digital gene expression data. Bioinformatics 26:139-140.

Rodgers AB, Morgan CP, Leu NA, and Bale TL (2015) Transgenerational epigenetic programming via sperm microRNA recapitulates effects of paternal stress. Proc Natl Acad Sci USA 112 13699-13704

Salian S, Doshi T, and Vanage G (2009) Perinatal exposure of rats to Bisphenol A affects the fertility of male offspring. Life Sci 85:742-752.

Schaefer C (2011) Drug safety in pregnancy: utopia or achievable prospect? Risk information, risk research and advocacy in Teratology Information Services. Congenit Anom (Kyoto) 51:6-11.

Schecter A, Colacino J, Haffner D, Patel K, Opel M, Päpke O, and Birnbaum L (2010) Perfluorinated compounds, polychlorinated biphenyls, and organochlorine pesticide contamination in composite food samples from Dallas, Texas, USA. Environ Health Perspect 118 796-802.

Skopp S, Oehme M, and Fürst P (2002) Enantiomer ratios, patterns and levels of toxaphene congeners in human milk from Germany. J Environ Monit 4:389-394.

Smith G, Henderson CJ, Parker MG, White R, Bars RG, and Wolf CR (1993) 1,4-Bis[2-(3,5dichloropyridyloxy)]benzene, an extremely potent modulator of mouse hepatic cytochrome P-450 gene expression. Biochem J 289:807-813.

Tanaka N, Aoyama T, Kimura S, and Gonzalez FJ (2017) Targeting nuclear receptors for the treatment of fatty liver disease. Pharmacol Ther 179:142-157.

Tayman C, Rayyan M, and Allegaert K (2011) Neonatal pharmacology: extensive interindividua variability despite limited size. J Pediatr Pharmacol Ther 16:170-184.

Tien YC, Liu K, Pope C, Wang P, Ma X, and Zhong XB (2015) Dose of phenobarbital and age of treatment at early life are two key factors for the persistent induction of cytochrome P450 enzymes in adult mouse liver. Drug Metab Dispos 43:1938-1945.

Tien YC, Piekos SC, Pope C, and Zhong XB (2017) Phenobarbital treatment at a neonatal age results in decreased efficacy of omeprazole in adult mice. Drug Metab Dispos 45:330-335.

Vassoler FM, White SL, Schmidt HD, Sadri-Vakili G, and Pierce RC (2013) Epigenetic inheritance of a cocaine-resistance phenotype. Nat Neurosci 16:42-47.

Wahlang B, Falkner KC, Clair HB, Al-Eryani L, Prough RA, States JC, Coslo DM, Omiecinski CJ, and Cave MC (2014) Human receptor activation by aroclor 1260, a polychlorinated bipheny mixture. Toxicol Sci 140:283-297.

Wang H and Tompkins LM (2008) CYP2B6: new insights into a historically overlooked cytochrome P450 isozyme. Curr Drug Metab 9:598-610.

Wang X, Sheng N, Cui R, Zhang H, Wang J, and Dai J (2017) Gestational and lactational exposure to di-isobutyl phthalate via diet in maternal mice decreases testosterone levels in male offspring. Chemosphere 172:260-267.

Wei P, Zhang J, Dowhan DH, Han Y, and Moore DD (2002) Specific and overlapping functions of the nuclear hormone receptors CAR and PXR in xenobiotic response. Pharmacogenomics $J \mathbf{2}$ : $117-126$.

Whitehead TP, Ward MH, Colt JS, Nishioka MG, Buffler PA, Rappaport SM, and Metayer C (2013) Determinants of polychlorinated biphenyls in dust from homes in California, USA. Environ Sci Process Impacts 15:339-346.

Williams E and Scott JP (1953) The development of social behavior patterns in the mouse, in relation to natural periods. Behaviour 6:35-65.

Wyde ME, Kirwan SE, Zhang F, Laughter A, Hoffman HB, Bartolucci-Page E, Gaido KW, Yan B, and You L (2005) Di-n-butyl phthalate activates constitutive androstane receptor and pregnane $X$ receptor and enhances the expression of steroid-metabolizing enzymes in the liver of rat fetuses. Toxicol Sci 86:281-290.

Xu J, Donepudi AC, More VR, Kulkarni SR, Li L, Guo L, Yan B, Chatterjee T, Weintraub N, and Slitt AL (2015) Deficiency in Nrf2 transcription factor decreases adipose tissue mass and hepatic lipid accumulation in leptin-deficient mice. Obesity (Silver Spring) 23:335-344.

Yamagata K, Furuta H, Oda N, Kaisaki PJ, Menzel S, Cox NJ, Fajans SS, Signorini S, Stoffel M, and Bell GI (1996) Mutations in the hepatocyte nuclear factor-4alpha gene in maturity-onset diabetes of the young (MODY1). Nature 384:458-460.

Yamazaki Y, Kakizaki S, Horiguchi N, Sohara N, Sato K, Takagi H, Mori M, and Negishi M (2007) The role of the nuclear receptor constitutive androstane receptor in the pathogenesis of non-alcoholic steatohepatitis. Gut 56:565-574.

Yang H and Wang H (2014) Signaling control of the constitutive androstane receptor (CAR). Protein Cell 5:113-123.

Yasmeen H, Qadir A, Mumtaz M, Eqani SAMAS, Syed JH, Mahmood A, Jamil N, Nazar F, Ali H, Ahmad MS, et al. (2017) Risk profile and health vulnerability of female workers who pick cotton by organanochlorine pesticides from southern Punjab, Pakistan. Environ Toxicol Chem 36: $1193-1201$

Zanger UM, Fischer J, Raimundo S, Stüven T, Evert BO, Schwab M, and Eichelbaum M (2001) Comprehensive analysis of the genetic factors determining expression and function of hepatic CYP2D6. Pharmacogenetics 11:573-585.

Zhang XJ, Shi Z, Lyv JX, He X, Englert NA, and Zhang SY (2015a) Pyrene is a novel constitutive androstane receptor (CAR) activator and causes hepatotoxicity by CAR. Toxicol Sci 147: 436-445.

Zhang Z, Zhou S, Jiang X, Wang YH, Li F, Wang YG, Zheng Y, and Cai L (2015b) The role of the Nrf2/Keap1 pathway in obesity and metabolic syndrome. Rev Endocr Metab Disord 16:35-45. Zhong HA, Mashinson V, Woolman TA, and Zha M (2013) Understanding the molecular properties and metabolism of top prescribed drugs. Curr Top Med Chem 13:1290-1307.

Ziv-Gal A, Wang W, Zhou C, and Flaws JA (2015) The effects of in utero bisphenol A exposure on reproductive capacity in several generations of mice. Toxicol Appl Pharmacol 284:354-362.

Address correspondence to: Dr. Marianne Mathäs, University Medical Center of the Johannes Gutenberg University Mainz, Obere Zahlbacher Straße 67, 55131 Mainz, Germany. E-mail: mathaes@uni-mainz.de 